\title{
Anaphylactic reaction to the first dose of subcutaneous methotrexate in JIA: a case report and literature review
}

\author{
Leonardo Campos ${ }^{1 *}$, Renata Sobral ${ }^{1}$, Vivian Almeida ${ }^{1}$, Rozana Almeida$^{2}$, Marise Lessa ${ }^{2}$, Christianne Diniz ${ }^{1}$ \\ Marta Rodrigues', Sheila Oliveira ${ }^{1}$, Flavio Sztajnbok ${ }^{2}$
}

From 21st European Pediatric Rheumatology (PReS) Congress

Belgrade, Serbia. 17-21 September 2014

\section{Introduction}

Methotrexate is the most used DMARD drug in the treatment of juvenile idiopathic arthritis and its efficacy has been demonstrated for more than 20 years. The usual dose is 10 to $15 \mathrm{mg} / \mathrm{m}^{2} /$ week. It is a safe and welltolerated drug by children and the most common side effects are gastrointestinal, hematologic and liver toxicity.

\section{Objectives}

To report a case of a 13-years old adolescent girl diagnosed with polyarticular JIA that had an anaphylactic reaction to the first dose of subcutaneous methotrexate.

\section{Methods}

Case report and literature review.

\section{Results}

A 13-years old adolescent girl diagnosed with polyarticular JIA (RF +/ANA-/HLA-B27-) received the first dose of subcutaneous methotrexate in our Day Care centre due to refractoriness to NSAIDs. While she was leaving the building after 10 minutes of medication she developed urticaria, angioedema, shortness of breath and hypoxia $\left(\mathrm{O}_{2}\right.$ saturation of $\left.85 \%\right)$. After administration of $0.5 \mathrm{ml}$ of $1: 1000$ adrenaline, $500 \mathrm{ml}$ of saline, $2.5 \mathrm{mg}$ of dexchlorpheniramine and $125 \mathrm{mg}$ of methylprednisolone she recovered and was discharged home after a short period of stay. The methotrexate she used was also for intrathecal administration and had only distilled water as suspension.

\section{Conclusion}

This is the first case report of anaphylaxis to methotrexate in a patient with JIA without previous exposure. Considering it is a very rare and fatal reaction, we suggest that the first subcutaneous dose should be administrated in a health center and the patient should wait 30 minutes before leave.

\section{Disclosure of interest}

None declared.

\section{Authors' details \\ ${ }^{1}$ Pediatric Rheumatology, Instituto de Pediatria e Puericultura Martagao Gesteira (IPPMG), Federal University of Rio de Janeiro, Brazil. ${ }^{2}$ Pediatric Rheumatology, Adolescent Health Care Center, State University of Rio de Janeiro (NESA/UERJ), Rio de Janeiro, Brazil.}

Published: 17 September 2014

doi:10.1186/1546-0096-12-S1-P200

Cite this article as: Campos et al:: Anaphylactic reaction to the first dose of subcutaneous methotrexate in JIA: a case report and literature review. Pediatric Rheumatology 2014 12(Suppl 1):P200. 